\title{
Computerized Posturographic Measurement in Elderly Women with Unilateral Knee Osteoarthritis
}

\author{
Kill-Byung Lim, M.D., Ph.D., Hong-Jae Lee, M.D. \\ Department of Rehabilitation Medicine, Ilsan Paik Hospital and Institute of Sports Rehabilitation, \\ Inje University College of Medicine, Goyang 411-706, Korea
}

\begin{abstract}
Objective To identify the subtle change of postural control in elderly patients with unilateral knee osteoarthritis (OA) with computerized dynamic posturography.

Method Twenty-two healthy women and twenty-six women with unilateral knee OA, aged 60 and over, were enrolled. The computerized posturographic measures included a weight bearing pattern during squatting and sit-to -stand, sway velocity of center of gravity (COG) during one leg standing, on-axis velocity and directional control of COG during rhythmic weight shift, rising index during sit-to-stand, end sway during tandem walk, and movement time during step up/over.

Results It was shown that patients bore significantly less weight on the affected side during the $30^{\circ}$ and $60^{\circ}$ squat and sit-to-stand. Sway velocity of COG during one leg standing was greater whereas the on-axis velocity and directional control during the front/back rhythmic weight shift were significantly lower in the patient group. The rising index during sit-to-stand was significantly lower and movement time during step up/over with the affected side was significantly longer in patients.

Conclusion This study demonstrated in detail a decline of postural balance by utilizing computerized posturography in elderly women with unilateral knee OA. They had less weight-bearing, more sway, and less ability of intentional postural control on the affected side.
\end{abstract}

Key Words Balance, Posture, Osteoarthritis, Knee

Received March 9, 2012; Accepted June 27, 2012

Corresponding author: Hong-Jae Lee

Department of Rehabilitation Medicine, Ilsan Paik Hospital, Inje University College of Medicine, 170, Juhwa-ro, Ilsanseo-gu, Goyang 411706, Korea

Tel: +82-31-910-7440, Fax: +82-31-910-7746, E-mail: honglee@paik.ac.kr (c) This is an open-access article distributed under the terms of the Creative Commons Attribution Non-Commercial License (http:// creativecommons.org/licenses/by-nc/3.0) which permits unrestricted noncommercial use, distribution, and reproduction in any medium, provided the original work is properly cited.

Copyright $\odot 2012$ by Korean Academy of Rehabilitation Medicine

\section{INTRODUCTION}

Balancing is a complex function involving numerous neuromuscular processes. It is dependent on a sensory input from the vestibular, visual, and somatosensory systems. The central processing of this information results in coordinated neuromuscular responses that ensure the center of mass remaining within the base of support in a situation where balance is disturbed. The effective control of balance relies not only on accurate sensory inputs but also on timely responses of strong muscles. ${ }^{1,2}$ 
Postural balance declines slowly in healthy individuals with age. ${ }^{3-5}$ As a result of the gradual deterioration of most sensory modalities and the rate of central information processing with aging slowing down, there is a decline in the speed of motor activities with gradual reductions in muscle mass, muscle fiber size, number of myofibrils, and concentration of mitochondrial enzymes. These changes are likely to lead to impaired postural balance in the geriatric populations. Dysfunction in postural balance increases the risk of falls and fall-related injuries in older adults. In fact, nearly one-third of those aged 75 and over fall at least once, and six percent sustain fractures over a 1 -year period. ${ }^{6}$ Fallers have more difficulty than non-fallers in performing tasks and position changes required for daily activities. The risk factors of falls include muscle weakness, poor balance, gait abnormalities, slow response times, and a number of medications as well as a number of pathological conditions and environmental hazards. ${ }^{6-8}$

Postural balance can be assessed subjectively by skilled clinicians or it can be assessed by grading performance during various maneuvers, such as walking, standing up, reaching, bending, and turning. Although these approaches may be useful for grossly identifying the balance deficits, computerized dynamic posturography can enhance the ability to identify more subtle balance impairment. So far, several posturographic machines have been developed in order to measure the subtle postural sway in various conditions.

Osteoarthritis (OA) of the knee joint, which is the most commonly afflicted weight-bearing joint, is one of the most prevalent musculoskeletal complaints worldwide, affecting $30-40 \%$ of the population by the age of 65 years. ${ }^{9}$ During its early stages, it is asymptomatic; but later in life, OA may result in pain, deformity, and restriction of joint motion, all of which may be disabling.

Knee OA combined with aging, which is the focus of this study, further attenuates strength and joint proprioception. More specifically, Messier et al. ${ }^{10}$ found a $22 \%$ reduction in the dominant legs and a $39 \%$ reduction in the non-dominant legs of the OA group in comparison of the isokinetic knee strength of 15 adults with knee OA and 15 healthy adults matched in age, sex, and body mass. In addition, Barrett et al. ${ }^{11}$ found that subjects with knee OA have poorer joint proprioception than the age-matched healthy controls. These changes might aggravate impaired postural control.
This study aims to identify the subtle change of postural control in patients with unilateral symptomatic knee OA in a geriatric population using computerized dynamic posturography. It also attempts to find out the relationship between posturographic measures and clinical measures.

\section{MATERIALS AND METHODS}

\section{Participants}

Twenty-six female patients with unilateral painful knee OA and twenty-two healthy female participants aged 60 and over were recruited for this study. All patients were able to carry out their daily activities without the help of others despite the fact that they had knee pain. The inclusion criteria were below; they have had unilateral knee pain most of the days for the previous year and regardless of NSAIDs medication, there was a degenerative change in the X-ray, as well as pain and difficulty when getting up from a chair or when climbing stairs. Subjects with a past history of knee surgery, such as joint replacement and rheumatic/psoriatic arthritis, severe medical conditions precluding safe testing or concurrent participation in another study were excluded from this study. In addition, participants in the control group were excluded if they reported any pain in either knee during the past year. For ethical reasons, X-rays conducted to rule out radiographic OA were not performed in healthy female participants.

The subjects gave informed consent to participate before the beginning of this study. This study was carried out under approval of the ethics committee of the university.

\section{Procedure}

Clinical measures: The knee pain scale used in this study was the intensity of knee pain experienced during ambulation and at rest. Measuring the intensity of the pain score was based on a 10-cm horizontal visual analog scale (VAS) marked in 1-cm increments. The ambulatory VAS score of the knee pain was recorded at the preferred walking speed on an even level in an outdoor area, while the resting VAS score was recorded at rest.

To assess the degenerative changes of the knee joint, participants with knee OA took X-rays (weight-bearing $\mathrm{AP}$, lateral and skyline views) of the painful knee. A radiologist rated the severity of the knee degeneration using 
the Kellgren-Lawrence Scale.

Computerized posturographic measures on the force platform: The computerized posturographic measures were obtained using the Balance Master System ${ }^{\circledR}$ (Neurocom Inc, Oregon, USA), which consists of a force platform and a computer. It is used to quantify body sway as well as measure the location of a subject's center of pressure related to the base of support. The platform consists of two adjacent $9 \times 60$-inch force-plates. The computer is located in front of the platform, and its screen is positioned at the subject's eye-level (Fig. 1). This system, with version 7.0 software, calculates the theoretical limit of stability (LOS) and the height of the center of gravity (COG) while standing on the force platform (Fig. 2). After COG of the body is computed, the system measures the amount of sway in any direction by sampling the vertical force. The COG sway angle is the angle between a vertical line projecting upward from the center of the area of feet support and a second line projecting from the same point to the subject's COG. The COG sway velocity is the ratio of the distance traveled by the COG (degrees) to the time (seconds) of the trial. The monitor that is connected to the force plate and computer gives the subject feedback of the current position of her COG with respect to the theoretical LOS. In order to eliminate the effect of footwear, the subjects were tested on barefoot.

We measured seven parameters using this system (Fig. 1). The first is the percentage of weight bearing (\% body weight), which is the ratio of the amount of weight borne on a side (left or right) to the patient's total body weight
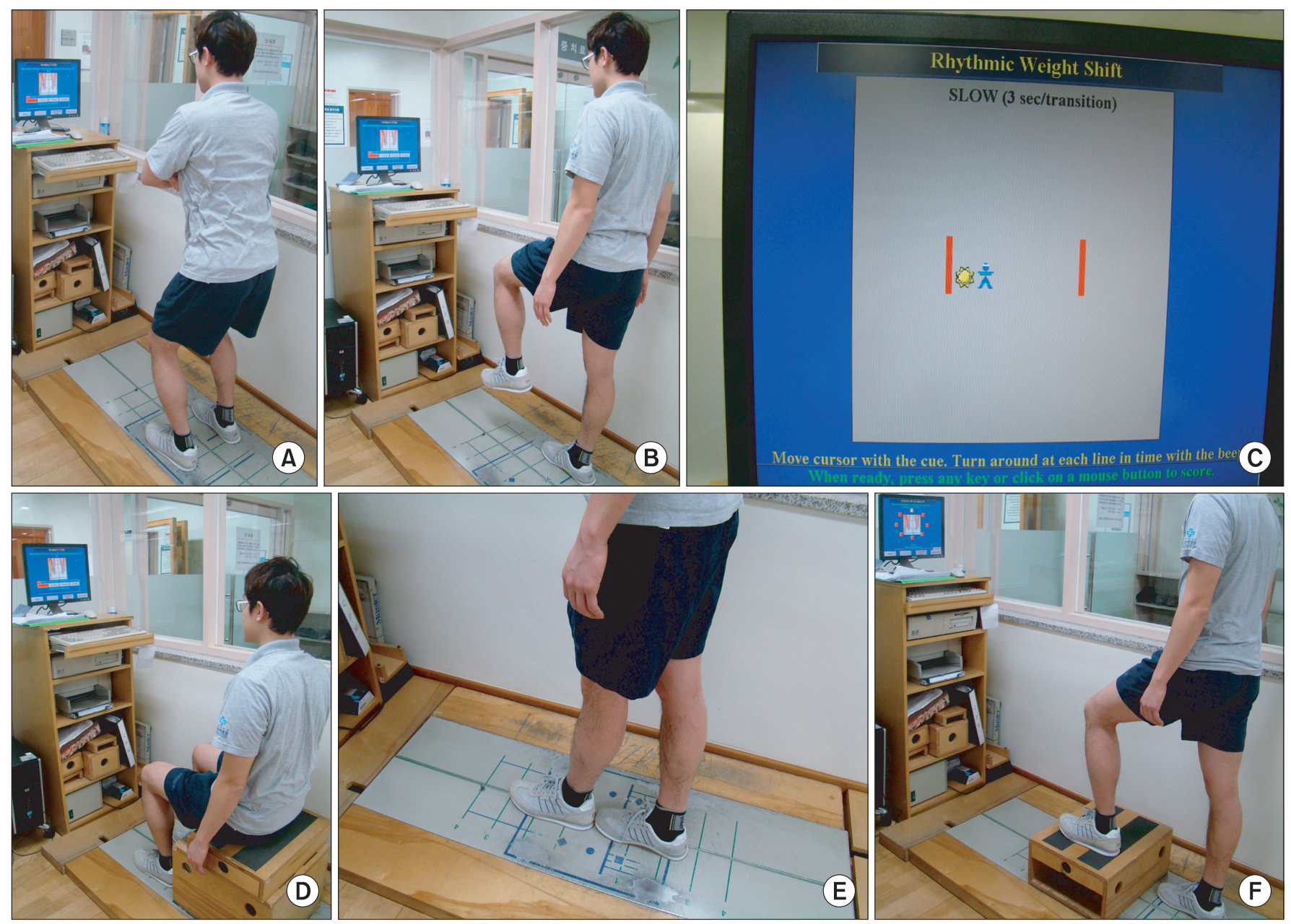

Fig. 1. Computerized posturographic measurement using the Balance Mater System ${ }^{\circledR}$, which consists of a force platform and a computer. Using this system, we measured the weight bearing pattern (A), sway velocity of center of gravity (COG) of the body during one leg standing (B), on-axis velocity and directional control during rhythmic weight shift (C), rising index during sit-to-stand (D), end sway during tandem gait (E), and movement time during step up/over task (F). 


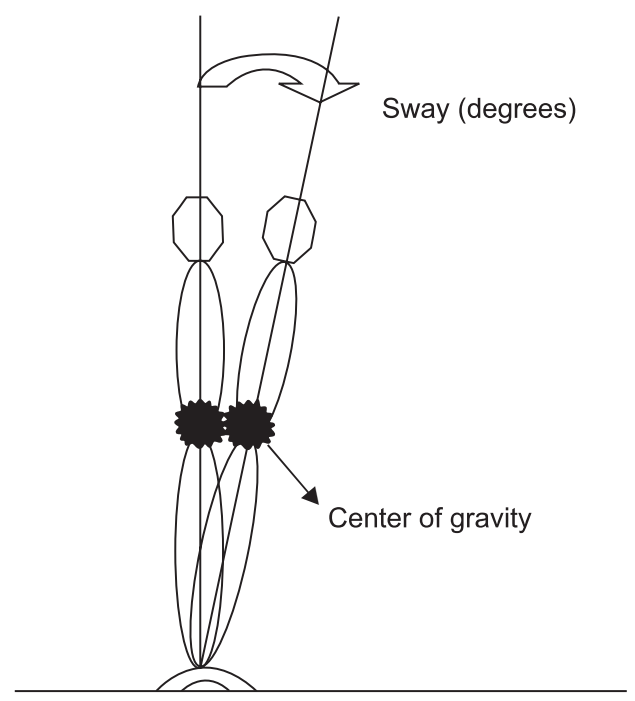

Fig. 2. Balance Master System ${ }^{\circledR}$ can measure the amount of sway in any direction by sampling the vertical force. The sway angle of the center of gravity (COG) is the angle between a vertical line projecting upward from the center of the area of feet support and a second line projecting from the same point to the subject's COG. The COG sway velocity is the ratio of the distance traveled by the COG (degrees) to the time (sec) of the trial.

(Fig. 1). These were measured with the patient squatting at the $30^{\circ}$ and $60^{\circ}$ of knee flexion on the forceplate, and standing up from a chair. If a side has less percentage than the other side, we decide the side to be borne less. The second is the unilateral stance test on a firm surface with their eyes open. The right and left legs were tested individually, and the sway of the COG $(\% / \mathrm{sec})$ was measured for 10 seconds per trial (Fig. 1). The third and fourth parameters were on-axis velocity $(\% / \mathrm{sec})$ and directional control (\%). These values were obtained during performing the rhythmic weight shift (Fig. 1). The subjects were asked to travel "to and from" and "right and left" between the endlines on the screen at the rate indicated by a cue. The pace set by the cue was 2 seconds per transition. On-axis velocity is the speed of COG movement in the intended direction, expressed as degrees per second. Directional control (\%) is the ratio of the amount of movement in the intended direction (toward the endline) to the amount of extraneous movement (away from the end line). The fifth parameter was the rising index (\% body weight) measured during the sit-to-stand task on the force plate. This means the average amount of force exerted by both legs during the rising phase, expressed as a percentage of body weight. The sixth parameter was

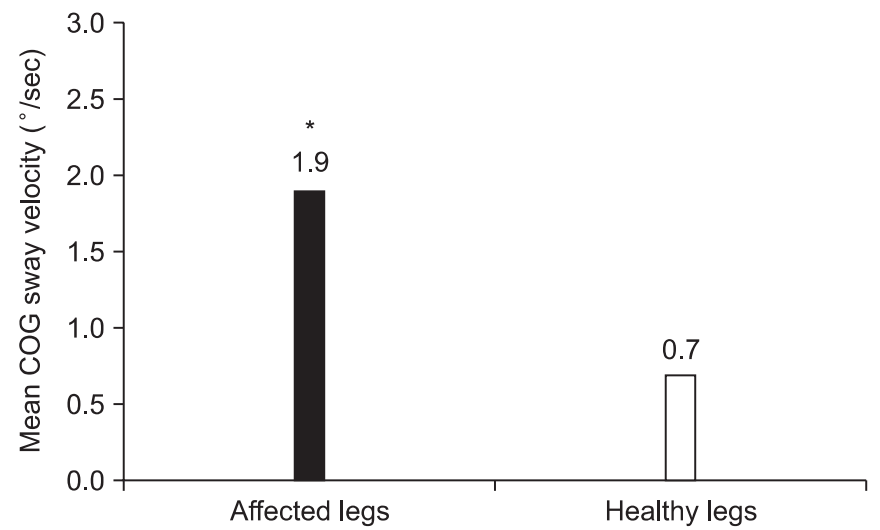

Fig. 3. One-leg standing test. There was a significant difference in the mean center of gravity (COG) and sway velocity $(\%$ sec) between the affected legs and healthy legs of the control $\left({ }^{*} \mathrm{p}=0.01\right)$.

end sway $(\% / \mathrm{sec})$ measured during tandem gait. This means the amount of sway of COG during tandem gait along a line on the force plate. The seventh parameter was the movement time measured during the step up/ over task. This means the amount of time spent to complete the step over, expressed in seconds.

All tasks were performed three times, and we used the mean values of data obtained from the 3 trials. We compared the mean values between patients with the unilateral symptomatic $\mathrm{OA}$ and the control group.

\section{Statistical analysis}

SAS software version 4.1 was used for all analyses. Descriptive statistics were generated for the characteristics of subjects with unilateral painful knee OA and the controls. We used Chi-squared analyses for the dichotomous variables of weight bearing pattern during squatting and sit-to-stand task, which were expressed as either being present or not. We used the independent $t$-test in order to determine the differences in the other six parameters between the unilateral painful knee OA group and the control group. Pearson's correlation analyses were performed in order to evaluate the relationship of the clinical measures and the computerized posturographic measures.

\section{RESULTS}

Comparing the two groups, there were no group differences in age and gender, while the subjects with unilater- 
al painful knee OA were significantly shorter and heavier than the control subjects (Table 1). On the KellgrenLawrence Scale, $24 \%, 37 \%, 21 \%$, and $18 \%$ of the patients were graded as I, II, III, and IV, respectively.

Table 2 demonstrated that the portions of the subjects with less weight bearing on the affected leg were 17 out of 26 patients $(65.4 \%)$ during the $30^{\circ}$ squat, 19 out of 26 patients (73.1\%) during the $60^{\circ}$ squat, and 17 out of 26 patients $(65.4 \%)$ during sit-to-stand. The affected side bore less weight than the other side with statistical significance in various positions.

During the unilateral stance on a firm surface with eyes open, the value of sway velocity $(\% / \mathrm{sec})$ of the COG were $1.9 \pm 1.1$ in the affected legs of patients and $0.7 \pm 0.5$ in the healthy legs of the control group. The sway velocity was significantly greater in the painful leg of patients $(p=0.01)$

Table 1. Demographic Characteristics of the Subjects

\begin{tabular}{lrrr}
\hline Characteristic & $\begin{array}{c}\text { Patient group } \\
(\mathbf{n}=\mathbf{2 6})\end{array}$ & $\begin{array}{c}\text { Control group } \\
(\mathbf{n}=\mathbf{2 2})\end{array}$ & p-value \\
\hline Age (years) & $67.0 \pm 8.9$ & $64.8 \pm 4.1$ & 0.12 \\
Height $(\mathrm{cm})$ & $152.6 \pm 6.7$ & $157.9 \pm 5.6$ & 0.04 \\
Weight $(\mathrm{kg})$ & $58.4 \pm 9.3$ & $53.4 \pm 5.9$ & 0.05 \\
\hline
\end{tabular}

Values are means \pm SD

Table 2. Weight-bearing Pattern during $30^{\circ}$ Squat, $60^{\circ}$ Squat, and Sit-to-stand Test in the Patient Group Who Had Unilateral Painful Knee OA

\begin{tabular}{lccc}
\hline & \multicolumn{3}{c}{$\begin{array}{c}\text { Less weight-bearing to } \\
\text { the affected knee }\end{array}$} \\
\cline { 2 - 4 } & Yes & No & No \\
\hline $30^{\circ}$ squat & $17(65.4 \%)$ & 9 & p-value \\
\hline $60^{\circ}$ squat & $19(73.1 \%)$ & 7 & 0.03 \\
Sit-to-stand & $17(65.4 \%)$ & 9 & 0.04 \\
\hline
\end{tabular}

Chi-squared test was used for the dichotomous variables above
(Fig. 3). The results implied that the patient group had more sway and were less stable during one leg standing with the affected knee.

On-axis velocity $(\% / \mathrm{sec})$ during the front/back rhythmic weight shift was $1.5 \pm 0.6$ in patents and $1.9 \pm 0.5$ in the control $(\mathrm{p}=0.03)$ group, meaning that the patient group had a slower front/back weight shift than the control group. On-axis velocity $(\% / \mathrm{sec})$ during the right/left rhythmic weight shift was $3.0 \pm 0.7$ in patients and $3.2 \pm 0.6$ in the control ( $\mathrm{p}=0.19)$ (Table 3$)$. There was no significant difference in these measures.

The directional control (\%) measured during the front/ back rhythmic weight shift was $52.5 \pm 7.5$ in patients and $67.7 \pm 18.7$ in the control $(\mathrm{p}=0.01)$, implying that the patient group has less ability for front/back directional control. The values during the right/left weight shifting was $81.2 \pm 5.2$ and $79.0 \pm 6.8$ in the patient group and the control group, respectively ( $\mathrm{p}=0.21$ ) (Table 3 ).

The rising index (\% body weight) in the sit-to-stand task was $12.1 \pm 4.8$ in patients and $15.8 \pm 7.1$ in the control group $(\mathrm{p}=0.02)$ (Table 4). This meant that the unilateral painful

Table 3. Comparison of Directional Control (\%) and Onaxis Velocity $(\%$ sec) during Rhythmic Weight Shift (Front/ Back, Right/Left) between Patient Group and the Control

\begin{tabular}{llccc}
\hline \multicolumn{1}{c}{ Parameter } & $\begin{array}{c}\text { Patient } \\
(\mathbf{n}=26)\end{array}$ & $\begin{array}{c}\text { Control } \\
(\mathbf{n}=22)\end{array}$ & $\begin{array}{c}\text { p- } \\
\text { value }\end{array}$ \\
\hline $\begin{array}{l}\text { Front/ } \\
\text { Back }\end{array}$ & $\begin{array}{c}\text { On-axis velocity } \\
(\% / \text { sec })\end{array}$ & $1.5 \pm 0.6$ & $1.9 \pm 0.5$ & 0.03 \\
$\begin{array}{l}\text { Directional control } \\
(\%)\end{array}$ & $52.5 \pm 7.5$ & $67.7 \pm 18.7$ & 0.01 \\
$\begin{array}{l}\text { Right/ } \\
\text { Left }\end{array}$ & $\begin{array}{l}\text { On-axis velocity } \\
(\% / \text { sec })\end{array}$ & $3.0 \pm 0.7$ & $3.2 \pm 0.6$ & 0.19 \\
& $\begin{array}{l}\text { Directional control } \\
(\%)\end{array}$ & $81.2 \pm 5.2$ & $79.0 \pm 6.8$ & 0.21 \\
\hline
\end{tabular}

Values are means \pm SD obtained from the independent $t$ test

Table 4. Comparison of Balance Parameters during Sit-to-stand, Tandem Walk, and Step Up/Over Tests between Patient Group and the Control

\begin{tabular}{llrrr}
\hline \multicolumn{1}{c}{ Test } & \multicolumn{1}{c}{ Parameter } & $\begin{array}{c}\text { Patient } \\
(\mathbf{n = 2 6 )}\end{array}$ & $\begin{array}{r}\text { Control } \\
(\mathbf{n = 2 2})\end{array}$ & p-value \\
\hline Sit-to-stand & Rising index (\% of BW) & $12.1 \pm 4.8$ & $15.8 \pm 7.1$ & 0.02 \\
Tandem walk & End sway ( $/ \mathrm{sec})$ & $4.0 \pm 1.6$ & $3.6 \pm 1.2$ & 0.11 \\
\hline Step up/over & Movement time (sec) & $1.8 \pm 1.1$ & $1.5 \pm 0.2$ & 0.04 \\
\hline
\end{tabular}

Values are means \pm SD obtained from the independent $t$-test

BW: Body weight 


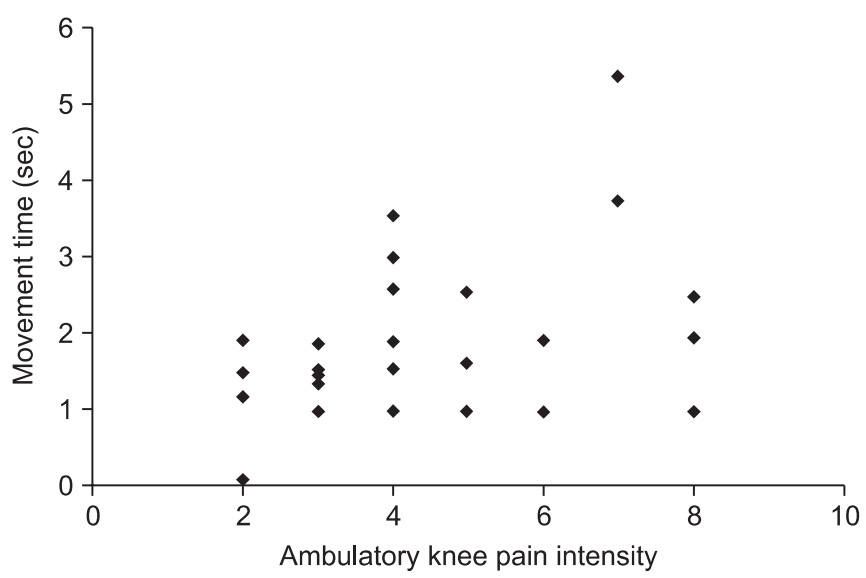

Fig. 4. The positive relationship between the movement time of the affected legs during the step up/over test and ambulatory knee pain intensity using a visual analog scale $(\mathrm{r}=0.42, \mathrm{p}=0.01)$.

knee OA group exerted a lower force during rising up.

The end sway $(\% / \mathrm{sec})$ during tandem gait was $4.0 \pm 1.6$ and 3.6 \pm 1.2 in each of the groups, which meant that there was no significant difference (Table 4).

The movement time of the affected side of patients in the step up/over task was $1.8 \pm 1.1$ seconds in patients and $1.5 \pm 0.2$ in the control $(\mathrm{p}=0.04)$ (Table 4$)$, which meant that the patients spent longer time to perform the task.

We conducted Pearson's correlation analysis between the computerized posturographic measures and the clinical measures, such as ambulatory knee pain intensity, resting knee pain intensity, and disease burden (Kellgren-Lawrence Scale). It showed that there was a linear relationship between the ambulatory knee pain intensity and the movement time of the affected side during step up/over ( $r=0.42, p=0.01$ ) (Fig. 4).

\section{DISCUSSION}

Although pain is the primary symptom of knee OA, the cause of the pain in an individual patient with $\mathrm{OA}$ is seldom easily explained by the physical and radiographic findings. An advanced stage based on radiographic criteria may be present in patients with minimal pain, and conversely, patients with little or no joint space narrowing may sometimes complain of disabling pain. Pain has an articular or periarticular source other than articular cartilage. The articular cartilage has no nerve supply; yet, the joint capsule, supporting ligaments, and perios- teum are innervated. The articular sensory fibers include low-threshold fibers activated by ordinary movement, high-threshold fibers activated by excessive movement or noxious stimuli, and small-diameter, unmyelinated fibers that do not react to mechanical stimuli. ${ }^{12}$ With the induction of experimental arthritis, the sensitivity of the high-threshold fibers is enhanced such that they are activated by movement within the normal range. The smalldiameter fibers are active even without mechanical stimulation, but they also become sensitive to motion. ${ }^{13}$ As OA progresses, the pattern of pain may evolve from pain related to motion and weight bearing to more persistent pain, which maybe intensified at night.

Arvidsson et al. ${ }^{14}$ demonstrates that the presence of pain might reflexively inhibit the muscles around the knee and that pain relief might play a significant role in the ability to normally activate the quadriceps muscle. The pain associated with knee OA disturbs the timely response of muscles, which is required for effective postural balance. Just as Hurwitz et al. ${ }^{15}$ suggested that pain results in a reduced loading of the affected joint, we find that the side bearing less weight is in significant agreement with the affected side during $30^{\circ}$ and $60^{\circ}$ squats and sit-to-stand.

In addition, the rising index (\% body weight) is lower in the unilateral painful knee OA group during sit-to-stand, implying that the force exerted by the patients' legs during the rising phase is weaker than that of the control group. These findings are of clinical significance. Activities such as squatting and sit-to-stand are important components of activities of daily life, and thus, difficulty of such activities potentially threatens an individual's ability to perform many of the daily life activities.

Patients with advanced OA often walk with an abnormal gait that is not well explained or directly related to the pain they experience. Al-Zahrani and Bakheit ${ }^{16}$ have shown that patients with severe OA of the knee have a significantly reduced walking speed, shorter stride length, and more prolonged stance phase in the gait cycle compared with those of the control subjects. They conclude that the observed gait abnormalities are attributable to the instability of the knee joint in stance. Some researchers have suggested that the observed pathologic widebased gait results from a decline of proprioception. ${ }^{17}$ Moreover, deficits in the lower limb proprioception and muscle strength are associated with knee $\mathrm{OA}^{18-20}$ and may 
also impair balance. Schaible et al. ${ }^{12}$ documented that adults aged 65 and over with chronic knee pain experienced a significant overall decline of the knee and ankle strength as well as balance during a voluntary anteroposterior sway test after a 30-month follow-up period.

The one-leg standing test on various support surfaces along with two visual conditions has been used for measuring the ability to control COG. However, we thought that conducting the test on a foam surface or with the eyes closed might not be suitable for discriminating the ability of the postural control between the two groups because it is a difficult task for elderly subjects in both groups. Therefore, for this study, we have decided to conduct the test on a firm surface with the eyes open.

The sway velocity of COG during one-leg standing was greater in painful legs than in either leg of healthy women. This result implies that the patient group had more sway and was less stable during one leg standing. Theoretically, however, it might be thought that the painful knee has to activate all muscle groups around the knee joint in order to stabilize the joint during one-leg standing, so that it would show less or equal sway compared to the normal group. However, in reality, this study showed the patients had more sway. Based on results of the current study, we can guess that the affected knee joints of the patients have had less proprioception for balancing and further, the joints have been vulnerable to mechanical stress such that degeneration would develop earlier than the unaffected knee joints. Similarly, Barrett et al. ${ }^{11}$ found that subjects with knee OA have poorer joint proprioception than age-matched healthy controls.

We found a significant difference between the two groups in the front/back rhythmic weight shift, whereas there was no significant difference in the right/left weight shift. The value of on-axis velocity during the front/back weight shift in the patient group was lower than that in the control group. Also, the value of directional control (\%) in the patient group during front/back weight shift was lower than that in the control group, whereas there was no significant difference in the value during the right/left weight shift. The results portray that it was difficult for unilateral knee OA patients to perform voluntary shifting forward and backward rather to do it side to side. However, Maki et al. ${ }^{21}$ reported that there were significant differences between fallers and non-fallers in the various measures related to spontaneous sway, anterior-posterior sway, and medial-lateral sway. Moreover, they reported that the lateral spontaneous sway amplitude was the single best predictor of future falling risk. It means that the protective mediolateral postural balancing is a very important factor that should be preserved to the end for the human gait and posture. Hence, the mediolateral balancing seems to be a crucial factor to differentiate fallers from non-fallers. However, the subjects of our study were patients who had knee OA in one leg, not fallers. Thus, we can guess that the ability for mediolateral balancing was well preserved in both groups in our study. Instead, patients with unilateral knee OA had more hesitation in voluntary weight shifting forward and backward on a narrower base of support in anterioposterior direction compared with the base of support in the mediolateral direction because the subjects were asked to open their legs wide to their pelvis width, not placing the feet together. Also, postural controlling during front/back weight shifting needs more activation of the quadriceps and hamstring muscles together, which can add a compressive force on the knee joint and may aggravate knee pain.

Radin et al. ${ }^{22}$ demonstrated that patients with knee pain have a faster transfer rate of force after the initial foot contact, presumably in order to avoid pain. We found that the movement time of the affected side during the step up/over was longer than that of the unaffected side, apparently contradicting Radin et al. This occurred probably in order to stabilize the arthritic knee and was associated with hesitation when stepping up on the curb owing to the anticipated knee pain after initial foot contact with the curb.

Our study demonstrated that the patients with unilateral painful knee OA had postural decline in many of the computerized dynamic posturographic measures. Several potential mechanisms may be associated with the change in the balance deficits in these patients, including lower limb proprioception, lower limb muscle strength, and pain. Based on our results, pain associated with limb loading appears to play an important role in the decline of postural balance.

The Pearson's correlation analysis between the computerized posturographic measures and the clinical measures, such as ambulatory knee pain intensity, resting knee pain intensity, and Kellgren-Lawrence Scale, showed that there was a strong positive relationship between the ambulatory knee pain intensity and the 
movement time of the affected side during step up/over. The greater the pain experienced during ambulation, the more time patients need in order to stabilize the arthritic knee or the longer they hesitate before stepping up on a curb. Interestingly, however, the knee pain intensity during resting had no relationship with the movement time. Unlike the ambulatory knee pain, the perception of resting knee pain and its severity is thought to be a more central phenomenon, and as such, is more dependent on factors unrelated to articular events or factors, such as psychological adjustment, family support, life style, and job satisfaction. Moreover, depression and anxiety have been found to be associated with knee pain in epidemiological studies. ${ }^{23,24}$ Thus, ambulatory knee pain intensity is considered a more reliable clinical parameter for predicting the impairment of postural balance than the resting knee pain intensity in patients with knee OA.

In the elderly population, the decline of postural control is a notorious risk factor in debilitating falls and is associated with poorer mobility. ${ }^{25-27}$ However, the direct relationship between the balance deficits identified in unilateral knee OA group and the occurrence of falls remains unknown in this study and hence, needs further investigation.

\section{Study limitations}

This experiment was confined to female subjects, making it difficult to generalize our results for both male and female patients with knee OA. Also, this study has a limitation stemming from its small sample size. However, our ultimate goal was aimed to find out the subtle change of postural control in the early stage of the elderly individual with symptomatic knee OA who are at risk of falling. This study sufficiently demonstrated such changes and may provide a basis for developing preventive actions to be taken before they experience a debilitating fall.

\section{CONCLUSION}

This study utilized the computerized posturographic measurement in order to demonstrate in detail the decline of postural control in elderly women with unilateral painful knee OA. They had less weight-bearing, more sway, and less ability of intentional postural control on the affected side.

It may provide a basis for developing preventive actions to be taken before the elderly experience a debilitating fall.

\section{ACKNOWLEDGEMENTS}

This study was supported by a Grant from Inje University, 2005.

\section{REFERENCES}

1. Horak FB, Shupert CL, Mirka A. Components of postural dyscontrol in the elderly: a review. Neurobiol Aging 1989; 10: 727-738

2. Stelmach GE, Teasdale N, Di Fabio RP, Phillips J. Age related decline in postural control mechanisms. Int J Aging Human Dev 1989; 29: 205-223

3. Aniansson A, Sperling L, Rundgren A, Lehnberg E. Muscle function in75-year-old men and women. A longitudinal study. Scan J Rehabil Med Suppl 1983; 9: 92-102

4. Overall PW, Exton-Smith AN, Imms FJ, Johnson AL. Fall in the elderly related to postural imbalance. $\mathrm{Br}$ Med J 1977; 1: 261-264

5. Rogers MA, Evans WJ. Changes in skeletal muscle with aging: effects of exercise training. Exerc Sport Sci Rev 1993; 21: 65-102

6. Tinetti ME, Speechley M, Ginter SF. Risk factors for falls among elderly persons living in the community. N Engl J Med 1988; 319: 1701-1707

7. Campbell AJ, Borrie MJ, Spears GF. Risk factors for falls in a community-based prospective study of people 70 years and older. J Gerontol 1989; 44: M112-117

8. Nevitt MC, Cummings SR, Kidd S, Black D. Risk factors for recurrent non-syncopal falls. A prospective study. JAMA 1989; 261: 2663-2668

9. van Saase JL, van Romude LK, Cats A, Vandenbroucke JP, Valkenburg HA. Epidemiology of osteoarthritis: zoetermeer survey. Comparison of radiological osteoarthritis in a Dutch population with that in 10 other populations. Ann Rheum Dis 1989; 48: 271-280

10. Messier SP, Loeser RF, Hoover JL, Semble EL, Wise CM. Osteoarthritis of the knee: effects on gait, strength, and flexibility. Arch Phys Med Rehabil 1992; 73: $29-36$

11. Barrett DS, Cobb AG, Bentley G. Joint proprioception in normal, osteoarthritic and replaced knees. J Bone 
Joint Surg Br 1991; 73: 53-56

12. Schaible HG, Neugebauer V, Schmidt RF. Osteoarthritis and pain. Semin Arthritis Rheum 1989; 18 Suppl 2: 30-34

13. Grigg P, Schaible H, Schmidt RF. Mechanical sensitivity in group III and IV afferents from posterior articular nerve in normal and inflamed cat knee. J Neurophysiol 1986; 5: 635-643

14. Arvidsson I, Eriksson E, Knutsson E, Arner S. Reduction of pain inhibition on voluntary muscle activation by epidural analgesia. Orthopedics 1986; 9: 1415-1419

15. Hurwitz DE, Ryals AR, Block JA, Sharma L, Schnitzer TJ, Andriacchi TP. Knee pain and joint loading in subjects with osteoarthritis of the knee. J Orthop Res 2000; 18: 572-579

16. Al-Zahrani KS, Bakheit AM. A study of the gait characteristics of patients with chronic osteoarthritis of the knee. Disabil Rehabil 2002; 24: 275-280

17. Gyory AN, Chao EY, Stauffer RN. Functional evaluation of normal and pathologic knees during gait. Arch Phys Med Rehabil 1976; 57: 571-577

18. Fisher NM, Pendergast DR. Reduced muscle function in patients with osteoarthritis. Scand J Rehabil Med 1997; 29: 213-221

19. Hurley MV, Scott DL, Rees J, Newham DJ. Sensorimotor changes and functional performance in patients with knee osteoarthritis. Ann Rheum Dis 1997; 56: 641-648

20. Pai YC, Rymer WZ, Chang RW, Sharma L. Effect of age and osteoarthritis on knee proprioception. Arthritis
Rheum 1997; 40: 2260-2265

21. Maki BE, Holliday PJ, Topper AK. A prospective study of postural balance and risk of falling in an ambulatory and independent elderly population. J Gerontol 1994; 49: M72-84

22. Radin EL, Yang KH, Riegger C, Kish VL, O'Connor JJ. Relationship between lower limb dynamics and knee joint pain. J Orthop Res 1991; 9: 398-405

23. Hochberg MC, Lawrence RC, Everett DF, CornoniHuntley J. Epidemiologic associations of pain in osteoarthritis of the knee: data from the National Health and Nutrition Examination Survey and the National Health and Nutrition Examination-I Epidemiologic Follow-up Survey. Semin Arthritis Rheum 1989; 18 Suppl 2: 4-9

24. Summers MN, Haley WE, Reveille JD, Alarcon GS. Radiographic assessment and psychologic variables as predictors of pain and functional impairment in osteoarthritis of the knee or hip. Arthritis Rheum 1988; 31: 204-209

25. Imms FJ, Edholm OG. Studies of gait and mobility in the elderly. Age Ageing 1981; 10: 147-156

26. Lichtenstein MJ, Shields SL, Shiavi RG, Burger MC. Clinical determinants of biomechanics platform measures of balance in aged women. J Am Geriatr Soc 1988; 36: 996-1002

27. Shumway-Cook A, Brauer S, Woollacott M. Predicting the probability for falls in community-dwelling older adults using the Timed Up \& Go Test. Phys Ther 2000; 80: 896-903 